\title{
Селективность гемосорбента «Анти-IgЕ-Гемо» для удаления из плазмы крови человека различных иммуноглобулинов
}

\author{
(C) 2021 Рябцева Т.В. ${ }^{1,2}$, Макаревич Д.А. ${ }^{1,3}$, Старостин А.В. ${ }^{2}$ \\ ${ }^{1}$ Белорусский государственный медицинский университет, Минск, Беларусь \\ ${ }^{2}$ МНПЦ хирургии, трансплантации и гематологии, Минск, Беларусь \\ ${ }^{3}$ Институт биоорганической химии НАН Беларуси, Минск, Беларусь
}

Поступила в редакцию 16.04.2021 г.

DOI: $10.17308 /$ sorpchrom.2021.21/3642

Для регулирования активности гуморального иммунитета и концентрации реактивных антител чаще всего используется плазмаферез, однако существует плазмасберегающая альтернатива - специфическая гемосорбция. Данный метод предполагает использование сорбентов с лигандом для извлечения из крови только определенного вида молекул, например, иммуноглобулинов. В Беларуси существует отечественное производство специфических гемосорбентов. Статья посвящена изучению сорбента, где активным лигандом является ароматическая аминокислота триптофан, которая обладает способностью взаимодействовать с Fc-фрагментом иммуноглобулинов класса G. Предметом исследования являлся анализ изменения концентрации общих иммуноглобулинов класса G, A, M и подклассов IgG1, IgG-2, IgG-3, IgG-4 после контакта с гемосорбентом. Проводились стендовые эксперименты, в которых моделировали геометрию и условия проведения экстракорпоральной гемосорбции у пациентов: продолжительность, температура, стерильность и условия потока (движения) крови с помощью перистальтического насоса, штатива, емкостей для забора и слива биоматериала. Результаты экспериментов показали, что после прохождения плазмы крови через гемосорбент происходит снижение концентрации альбумина и глобулина. Полученные результаты свидетельствуют о высокой эффективности исследуемого гемосорбента в отношении всех основных классов иммуноглобулинов. Рассчитанная эффективность сорбции для IgG составила 44.89 (37.24; 46.27)\%, для IgM - 31.83 (31.73; 39.74)\%, для IgA - $22.25(12.64 ; 25.08) \%$, для IgE - 13.91 (9.76; 16.37)\%. Исследования выявили различия в эффективности сорбции подклассов IgG. Количество IgG-3 в плазме после экспериментов уменьшалось более чем на $50 \%$ от исходной концентрации, рассчитанная эффективность сорбции для IgG-3 составила 51.23 $(45.65 ; 63.84) \%$, для IgG-2 - 31.25 (26.54; 33.21)\%, для IgG-1 - 23.26 (15.45; 25.30)\%, для IgG-4 - 31.91 $(23.61 ; 33.25) \%$. Таким образом, данный гемосорбент может быть рекомендован для применения у пациентов с заболеваниями, патогенез которых связан с участием данных иммуноглобулинов: аутоиммунные заболевания, реакции отторжение, гипергаммаглобулинемии и др.

Ключевые слова: гемосорбент, сорбция, иммуноглобулин $\mathrm{G}$, плазма крови, специфичность сорбции.

\section{Введение}

Для регулирования активности гуморального иммунитета и концентрации реактивных антител чаще всего используется плазмаферез, при этом жидкая часть крови (плазма), содержащая патологические метаболиты удаляется из организма при центрифугировании цельной крови, а часть крови, содержащая форменные элементы, возвращается пациенту. У данного метода имеется существенный недостаток: с удаленной плазмой из крови извлекаются необходимые физиологически активные вещества. В случае извлечения большого объема плазмы, необходимо проводить заместительную терапию донорскими препаратами крови, которые являются чужеродными и могут вызвать 
дополнительную нежелательную иммунологическую активность.

На сегодняшний день существует альтернатива плазмаферезу - специфическая гемосорбция. Данный метод предполагает использование сорбентов с лигандом для извлечения из крови только определенного вида молекул, например, иммуноглобулинов. Основными производителями гемосорбентов в мире являются Япония, Германия, Россия, Швеция, США. Японская компания Asahi Medical предлагает два типа колонок для плазмоперфузии, основанных на использовании иммобилизованных аминокислот триптофана и фенилаланина [1]. Данные сор- бенты применяются для лечения широкого круга аутоиммунных заболеваний, сопровождающихся нарастанием концентрации аутореактивных антител в крови пациентов. Для связывания иммуноглобулинов также используют как плазмосорбенты, так и гемосорбенты, содержащие в качестве лигандов декстран сульфат (Германия, Япония), протеин А (США, Швеция), поликлональные антитела (Германия, Россия), субкомпонент системы комплемента C1q (Германия), синтетические пептиды (Япония) [1-5]. Подробнее показатели гемосорбентов для удаления иммуноглобулинов класса $\mathrm{G}$ представлены в таблице 1 .

Таблица 1. Техническая характеристика сорбентов для избирательного удаления иммуноглобулинов [1-5]

Table 1. Technical characteristics of sorbents for selective removal of immunoglobulins [1-5]

\begin{tabular}{|c|c|c|c|c|c|c|c|}
\hline & Selesorb & $\begin{array}{c}\text { IM- } \\
\text { TR350, } \\
\text { IM- } \\
\text { PH350 }\end{array}$ & Prosorba & $\begin{array}{c}\text { Immuno- } \\
\text { sorba }\end{array}$ & $\begin{array}{l}\text { Ig- } \\
\text { therasorb }\end{array}$ & Miro & $\begin{array}{c}\text { Анти } \\
\text { IgE-гемо }\end{array}$ \\
\hline $\begin{array}{c}\text { Страна- } \\
\text { произ- } \\
\text { води- } \\
\text { тель }\end{array}$ & $\begin{array}{c}\text { Герма- } \\
\text { ния }\end{array}$ & Япония & $\begin{array}{c}\text { Герма- } \\
\text { ния }\end{array}$ & $\begin{array}{c}\text { Герма- } \\
\text { ния }\end{array}$ & $\begin{array}{c}\text { Герма- } \\
\text { ния }\end{array}$ & $\begin{array}{c}\text { Герма- } \\
\text { ния }\end{array}$ & Беларусь \\
\hline $\begin{array}{c}\text { Актив- } \\
\text { ный ли- } \\
\text { ганд }\end{array}$ & $\begin{array}{c}\text { Дек- } \\
\text { стран- } \\
\text { сульфат }\end{array}$ & $\begin{array}{c}\text { Трипто- } \\
\text { фан, фе- } \\
\text { нилала- } \\
\text { нин }\end{array}$ & $\begin{array}{c}\text { Про- } \\
\text { теин-А }\end{array}$ & $\begin{array}{c}\text { Про- } \\
\text { теин-А }\end{array}$ & $\begin{array}{c}\text { Полик- } \\
\text { лональ- } \\
\text { ные ове- } \\
\text { чьи ан- } \\
\text { тиIg ан- } \\
\text { титела }\end{array}$ & $\begin{array}{c}\text { C1q-ли- } \\
\text { ганд }\end{array}$ & $\begin{array}{c}\text { Трипто- } \\
\text { фан }\end{array}$ \\
\hline $\begin{array}{c}\text { Матри- } \\
\text { ца }\end{array}$ & $\begin{array}{c}\text { Поли- } \\
\text { сульфон }\end{array}$ & $\begin{array}{c}\text { Поливи- } \\
\text { ниловый } \\
\text { спирт }\end{array}$ & $\begin{array}{c}\text { Силикат } \\
\text { (крем- } \\
\text { ниевый } \\
\text { анги- } \\
\text { дрид) }\end{array}$ & $\begin{array}{c}\text { Cефаро- } \\
\text { за }\end{array}$ & $\begin{array}{c}\text { Ceфаро- } \\
\text { за }\end{array}$ & $\begin{array}{c}\text { Поли-ак- } \\
\text { рилат }\end{array}$ & $\begin{array}{c}\text { Поли- } \\
\text { акри-ла- } \\
\text { мид }\end{array}$ \\
\hline $\begin{array}{c}\text { Объем } \\
\text { колонки, } \\
\mathrm{cm}^{3}\end{array}$ & 150 & 350 & 300 & 62.5 & 300 & 300 & 55 \\
\hline $\begin{array}{c}\text { Объем } \\
\text { заполне- } \\
\text { ния, } \text { см }^{3} \\
\end{array}$ & 1000 & 300 & 100 & 72.5 & 100 & 290 & 70 \\
\hline $\begin{array}{c}\text { Специ- } \\
\text { фич- } \\
\text { ность }\end{array}$ & $\begin{array}{c}\text { Липиды, } \\
\text { фибри- } \\
\text { ноген, } \\
\text { иммуно- } \\
\text { глобу- } \\
\text { лины }\end{array}$ & $\begin{array}{c}\text { Имму- } \\
\text { ноглобу- } \\
\text { лины, } \\
\text { фиб-ри- } \\
\text { ноген }\end{array}$ & $\begin{array}{c}\operatorname{IgG}, \operatorname{IgA}, \\
\operatorname{IgM}\end{array}$ & $\begin{array}{c}\operatorname{IgG}, \operatorname{Ig} \mathrm{A}, \\
\operatorname{IgM}\end{array}$ & $\begin{array}{c}\operatorname{IgG}, \operatorname{IgA}, \\
\text { IgM }\end{array}$ & $\begin{array}{c}\text { С1q- } \\
\text { ЦИК, } \\
\text { С1q-ан- } \\
\text { титела, } \\
\text { фибри- } \\
\text { ноген }\end{array}$ & $\begin{array}{c}\text { Иммуно- } \\
\text { глобу- } \\
\text { лины }\end{array}$ \\
\hline $\begin{array}{l}\text { Цена, } \\
\text { EUR }\end{array}$ & 1000.00 & 650.00 & 1000.00 & 10000.00 & 15000.00 & 1900.00 & 80.00 \\
\hline
\end{tabular}


В Беларуси существует отечественное производство специфических гемосорбентов. В одном из таких сорбентов активным лигандом является ароматическая аминокислота триптофан, которая, как известно, обладает способностью взаимодействовать с Fc-фрагментом иммуноглобулинов класса G [6]. Существуют данные о способности данного сорбента извлекать иммуноглобулины класса $\mathrm{E}$, но нет данных о способности извлечения $\mathrm{IgG}$, а также различных подклассов IgG1, IgG-2, IgG-3, IgG-4.

Цель работы - оценка эффективности и селективности гемосорбента «Анти$\operatorname{IgE»~для~сорбции~различных~подклассов~}$ иммуноглобулина $\mathrm{G}$ из плазмы крови человека in vitro.

\section{Экспериментальная часть}

Во время исследования проводили оценку параметров сорбции различных иммуноглобулинов из плазмы крови с помощью отечественного гемосорбента в стендовом варианте экстракорпоральной гемосорбции.

Основной задачей для достижения цели являлось проведение серии стендовых экспериментов, в которых моделируется геометрия и условия проведения экстракорпоральной гемосорбции у пациентов: продолжительность, температура, стерильность и условия потока (движения) крови с помощью перистальтического насоса, штатива, емкостей для забора и слива биоматериала. Время эксперимента составляло 50-60 мин (скорость тока плазмы - 5-10 см $3 /$ мин.) при комнатной температуре. Пробы (по $1 \mathrm{~cm}^{3}$ ) отбирали из емкости с исходным биоматериалом $\left(\mathrm{V}=500 \mathrm{~cm}^{3}\right)$ до эксперимента и после окончания эксперимента (из второй емкости $\left(\mathrm{V}=500 \mathrm{~cm}^{3}\right)$. Пробы маркировали и замораживали для последующего определения концентрации белков плазмы крови.

В качестве источника исследуемых биомолекул использовали плазму пациентов с кризом отторжения после ортотопической трансплантации печени (ОТП), полученную после проведения большеобъемного плазмафереза. Данный биоматериал характеризовался потенциально высокими концентрациями гуморальных факторов иммунитета, сопровождающих кризы отторжения. Объектом исследования являлся гемосорбент отечественного совместного производства НПО ОДО «Фармавит» и ГНУ «Институт биоорганической химии НАН Беларуси». Данный гемосорбент внесен в «Государственный реестр медицинской техники и изделий медицинского назначения Республики Беларусь» (N государственной регистрации ИМ-7.101661/2004 от 30.04.2020). В качестве активного лиганда в данном изделии медицинского назначения используется ароматическая аминокислота триптофан, ковалентно иммобилизованная на полиакриламидном геле. Гемосорбент представляет собой одноразовую емкость, заполненную гелем, с входящей и исходящей магистралями для обеспечения тока крови. В результате прохождения биоматериала сквозь гемосорбент происходит изменение биохимического состава пробы за счет гидрофобных и ионных взаимодействий молекул иммуноглобулинов с активным лигандом с активным лигандом. Предметом настоящего исследования являлось изменение концентрации общих иммуноглобулинов класса $\mathrm{G}, \mathrm{A}, \mathrm{M}$ и подклассов IgG-1, IgG-2, IgG-3, IgG-4 после контакта с гемосорбентом. Концентрация биомолекул оценивалась иммуноферментным методом с помощью планшетного спектрофотометра Multiskan (Финляндия). Эффективность сорбции в процентах рассчитывали по формуле:

$$
Э=\frac{\Delta \operatorname{Ig} \cdot 100 \%}{\operatorname{Ig} \text { исх }}
$$

где $\Delta \mathrm{Ig}$ - изменение количества иммуноглобулина в пробе, г, Ig исх. - исходное количество иммуноглобулина в пробе, г.

Статистическая обработка информации проводилась методами непараметрической статистики с помощью программы Statistica 10.0. Результаты представлялись медианой, 25-м и 75-м персентилем. 
Таблица 2. Изменения протеинограммы после сорбции на гемосорбенте с триптофаном Table 2. Changes in proteinogram after sorption on hemosorbent with tryptophan

\begin{tabular}{|c|c|c|c|}
\hline & Общий белок, г/дм ${ }^{3}$ & Альбумин, г/дм ${ }^{3}$ & Глобулины, г/дм ${ }^{3}$ \\
\hline До сорбции & $60.9(59.3 ; 65.2)$ & $29.2(27,4 ; 31,2)$ & $31.7(29.5 ; 33.7)$ \\
\hline После сорбции & $55.6(49.5 ; 59.4)$ & $25.9(23,6 ; 28,5)$ & $29.7(27.4 ; 31.4)$ \\
\hline \% сорбции & $8.70(7.59 ; 9.13)$ & $11.30(10,22 ; 13,65)$ & $6.31(5.98 ; 8.63)$ \\
\hline
\end{tabular}

\section{Обсуждение результатов}

Результаты исследования изменения концентрации общего белка, альбумина и глобулинов в ходе сорбции на гемосорбенте представлены в таблице 2 .

Исследования показали, что после контакта биоматериала с гемосорбентом, происходит снижение концентрации альбумина и глобулина.

Результаты стендового эксперимента по определению эффективности элиминации основных классов иммуноглобулинов из плазмы пациентов после ОТП в процессе физико-химического эксперимента представлены в таблице 3. Полученные значения свидетельствуют о высокой эффективности исследуемого гемосорбента в отношении всех основных классов иммуноглобулинов. Как видно из полученных результатов через 15 минут эксперимента в пробах отмечается увеличение концентрации иммуноглобулинов, что может свидетельствовать о том, что при прохождении плазмы через контур с массообменным устройством, содержа- щим гемосорбент, происходит распад иммунных комплексов, присутствующих в плазме и высвобождаются свободные молекулы иммуноглобулинов. Увеличение концентрации иммуноглобулинов класса М и А еще также может быть связано с тем, что эти белки представлены в плазме в виде пентамера и димера, соответственно. Прохождение плазмы через гемосорбционную колонку может приводить к разрушению данных комплексов и увеличению концентрации иммуноглобулинов, определяемой на пятнадцатой минуте эксперимента. Разрушение данных комплексов способствует незначительному снижению концентрации данных белков в пробе, так как происходит высвобождение Fc-фрагмента молекулы, через который происходит взаимодействие белка с иммобилизованным лигандом.

Высокая сорбционная активность отмечается для IgG. Количество $\mathrm{IgG}$ в $500 \mathrm{~cm}^{3}$ плазмы после экспериментов

Таблица 3. Изменение концентрации основных классов иммуноглобулинов в плазме крови человека в процессе физико-химического эксперимента

Table 3. Changes in the concentration of the main immunoglobulin classes in human plasma during a physicochemical experiment

\begin{tabular}{|c|c|c|c|c|}
\hline Класс Ig & $\mathrm{IgG}$, г/дм ${ }^{3}$ & IgA, мг/дм ${ }^{3}$ & $\operatorname{IgM}$, мг/дм ${ }^{3}$ & $\mathrm{IgE}, \mathrm{мГ} /$ дм $^{3}$ \\
\hline $\begin{array}{ll}\text { До } & \text { сорбции } \\
\text { (проба из всего } \\
\text { объема плазмы) }\end{array}$ & $\begin{array}{c}18.39 \\
(14.31 ; 27.13)\end{array}$ & $\begin{array}{c}573.50 \\
(487.12 ; 792.61)\end{array}$ & $\begin{array}{c}1622.74 \\
(1218.40 ; 1822.34)\end{array}$ & $\begin{array}{c}0.61 \\
(0.54 ; 2.55)\end{array}$ \\
\hline $\begin{array}{l}15 \text { мин. } \\
\text { сорбции (проба } \\
\text { из контура) }\end{array}$ & $\begin{array}{c}20.37 \\
(13.99 ; 25.24)\end{array}$ & $\begin{array}{c}698.94 \\
(602.33 ; 710.92)\end{array}$ & $\begin{array}{c}2620.13 \\
(1788.99 ; 2687.00)\end{array}$ & $\begin{array}{c}0.67 \\
(0.61 ; 2.44)\end{array}$ \\
\hline $\begin{array}{l}30 \text { мин. сорб- } \\
\text { ции (проба из } \\
\text { контура) }\end{array}$ & $\begin{array}{c}13.36 \\
(11.25 ; 17.74)\end{array}$ & $\begin{array}{c}505.72 \\
(314.43 ; 571.30)\end{array}$ & $\begin{array}{c}957.87 \\
(691.47 ; 1424.70)\end{array}$ & $\begin{array}{c}0.52 \\
(0.37 ; 2.37)\end{array}$ \\
\hline $\begin{array}{l}\text { После сорбции } \\
\text { (проба из всего } \\
\text { объема плазмы) }\end{array}$ & $\begin{array}{c}12.49 \\
(10.71 ; 16.37)\end{array}$ & $\begin{array}{c}396.06 \\
(361.69 ; 477.34)\end{array}$ & $\begin{array}{c}1107.90 \\
(763.82 ; 1904.03)\end{array}$ & $\begin{array}{c}0.68 \\
(0.47 ; 2.27)\end{array}$ \\
\hline
\end{tabular}




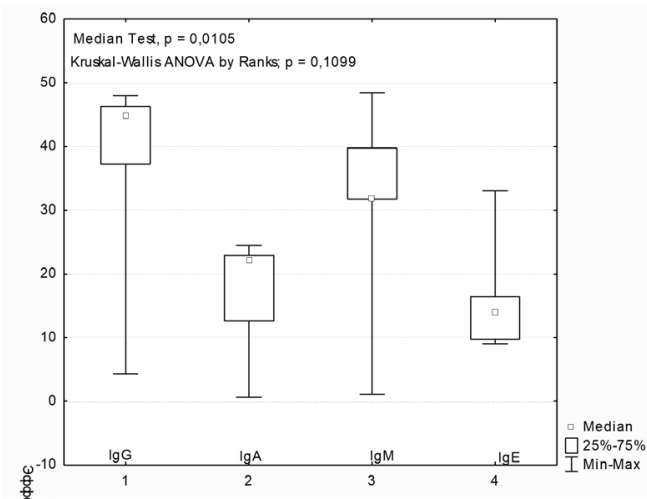

Рис. 1. Эффективность сорбции различных классов иммуноглобулинов

Fig. 1. Sorption efficiency

of different immunoglobulin classes

уменьшалось в среднем на 3.41 (3.01; 4.90) г, $\operatorname{IgM}$ - на $0.22(0.20 ; 0.26)$ г, $\operatorname{IgA}-$ на $0.08(0.04 ; 0.09)$ г, $\operatorname{IgE}-$ на 0.0009 $(0.00007 ; 0.0003)$ г. Рассчитанная эффективность сорбции для $\mathrm{IgG}$ составила $44.89(37.24 ; 46.27) \%$, для $\operatorname{IgM}-31.83$ (31.73; 39.74)\%, для IgA - 22.25 (12.64; $25.08) \%$, для $\operatorname{IgE}-13.91(9.76 ; 16.37) \%$ (рис. 1).

Медианный тест подтвердил статистическую значимость между эффективностью сорбции различных классов иммуноглобулинов. Таким образом, можно говорить о селективном извлечении $\operatorname{IgG}$ из плазмы крови человека с помощью гемосорбента с лигандом L-триптофан.

Результаты стендового эксперимента по определению эффективности элиминации подклассов IgG: IgG-1, IgG-2, IgG$3, \mathrm{IgG}-4$ из плазмы пациентов после ОТП в процессе стендового эксперимента на гемосорбенте представлены в таблице 4. Данные свидетельствуют о различии в

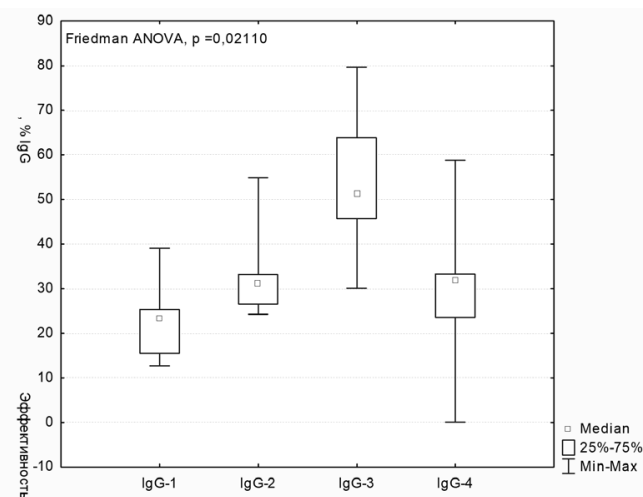

Рис. 2. Эффективность сорбции различных подклассов IgG Fig. 2. Sorption efficiency of various $\operatorname{IgG}$ subclasses

эффективности в отношении всех подклассов IgG. Высокая сорбционная активность отмечается для IgG-3. Количество IgG-3 в плазме после экспериментов уменьшалось более чем на $50 \%$ от исходной концентрации, рассчитанная эффективность сорбции для IgG-3 составила 51.23 (45.65; 63.84)\%, для IgG-2 - 31.25 $(26.54 ; 33.21) \%$, для IgG-1 - 23.26 (15.45; $25.30) \%$, для IgG-4 - 31.91 (23.61; 33.25)\% (рис. 2).

Данные различия в эффективности сорбции объясняются в первую очередь однородностью химического строения тяжелых цепей всех подклассов иммуноглобулинов класса G. IgG3 подкласса отличаются от остальных подклассов более массивной шарнирной зоной, что во многом увеличивает их конформационную подвижность и, как следствие, аффинность и авидность IgG3 антител. Именно массивностью шарнирной зоны IgG3 можно объяснить более высокий

Таблица 4. Изменение концентрации основных подклассов IgG в плазме крови человека в процессе эксперимента

Table 4. Changes in the concentration of the main IgG subclasses in human plasma during a physicochemical experiment

\begin{tabular}{|c|c|c|c|c|}
\hline подкласс IgG & IgG-1, г/дм & IgG-2, г/дм & IgG-3, г/дм & IgG-4, г/дм $^{3}$ \\
\hline До сорбции & 11.62 & 3.77 & 2.59 & 0,41 \\
(проба из всего объема плазмы) & $(8.48 ; 12.97)$ & $(3.32 ; 4.93)$ & $(2.13 ; 8.55)$ & $(0.38 ; 0.68)$ \\
\hline 15 мин. сорбции & 9.37 & 4.21 & 3.31 & 0.48 \\
(проба из контура) & $(7.72 ; 11.04)$ & $(3.51 ; 4.66)$ & $(2.34 ; 8.91)$ & $(0.42 ; 0.63)$ \\
\hline 30 мин. сорбции & 8.69 & 2.83 & 1.36 & 0.48 \\
(проба из контура) & $(7.36 ; 10.33)$ & $(2.61 ; 4.06)$ & $(0.94 ; 2.78)$ & $(0.31 ; 0.57)$ \\
\hline После сорбции (проба из всего & 8.72 & 2.20 & 1.17 & 0.40 \\
объема плазмы) & $(7.42 ; 10.59)$ & $(1.96 ; 3.19)$ & $(1.06 ; 2.07)$ & $(0.27 ; 0.52)$
\end{tabular}


процент связывания, так как именно через взаимодействие шарнирной области с заряженными группами триптофана обуславливается адсорбция IgG.

Существует много исследований, посвященных участию различных подклассов IgG в патогенезе аутоиммунных заболеваний. Было показано, что сывороточные $\operatorname{IgG1}$ (IgG1/IgG) и/или $\mathrm{IgG3}$ (IgG3/IgG) повышаются при первичном синдроме Шегрена, системной красной волчанке, системном склерозе и первичном билиарном холангите. Кроме того, существует положительная корреляция между уровнем IgG3 и длительностью заболевания [7].

\section{Список литературы}

1. Sueoka A. // Ther. Apher. 1997. Vol. 1. iss. 3. pp. 271-283.

2. Wiesenhuter C., Irish B., Bertram J. // J. Rheumatol. 1994. Vol. 21. iss. 5. pp. 804-812.

3. Braun N., Risler T. // Ther. Apher. 1999. Vol. 3. iss. 3. pp. 240-245.

4. Oka K., Nakaji, S., Ide Y., Okumura S. // Jpn. J. Artif. Organs. 1993. Vol. 22. pp. 194-197.

\section{Заключение}

Можно сделать вывод об эффективности гемосорбента «Анти-IgE- Гемо» с лигандом L-триптофан для удаления IgG, наиболее эффективное снижение концентрации отмечается для IgG3. В связи с чем данный гемосорбент может быть рекомендован для применения у пациентов с заболеваниями, патогенез которых связан с участием данных иммуноглобулинов: аутоиммунные заболевания, реакции отторжение, гипергаммаглобулинемии и др.

5. Pokrovsky S., Kuznetsova Y., Afanasieva O., Zvezdkin P. // Therapeutic Apheresis and Dialysis. 2005. Vol. 9. iss. 5. pp. A38.

6. Beena M.S., Chandy T., Sharma C.P. // J Biomater.Appl. 1994. Vol. 8. iss. 4. pp. 385-403.

7. Napodano C., Marino M.-P., Stefanile A. et al. // A Journal of Molecular and Cellular Immunology. Immunological investigations. 2020. No 11. pp. 1-19.

\title{
Selectivity of the "Anti-IgE-Hemo" hemosorbent for the removal of various immunoglobulins from human plasma
}

\author{
(C) 2021 Ryabtseva T.V. ${ }^{1,2}$, Makarevich D.A. ${ }^{1,3}$, Starostin A.V. ${ }^{2}$ \\ ${ }^{1}$ Belarus State Economic University, Minsk, Belarus \\ ${ }^{2}$ Minsk Research Centre for Surgery, Transplantation, and Hematology, Minsk, Belarus \\ ${ }^{3}$ Institute of Bioorganic Chemistry of the National Academy of Sciences of Belarus, Minsk, Belarus
}

\begin{abstract}
Plasmapheresis is one of the most common procedures used to regulate the activity of humoral immunity and the concentration of reactive antibodies. However, there is a plasma-saving alternative, specific hemosorption. This method involves using sorbents with ligands to only extract a certain type of molecule, for example, immunoglobulins, from the blood. Belarus produces specific hemosorbents domestically. The article is devoted to the study of the sorbent with a ligand in a form of an aromatic amino acid, tryptophan, which can interact with the Fc-fragment of immunoglobulins $\mathrm{G}$. The subject of the study was the analysis of changes in the concentration of total immunoglobulins $\mathrm{G}, \mathrm{A}$, and $\mathrm{M}$ and their subclasses IgG-1, IgG-2, IgG-3, and IgG-4 after contact with a hemosorbent. Bench experiments were carried out, in which the geometry and conditions of extracorporeal hemosorption in patients were simulated: duration, temperature, sterility, and the conditions of the blood flow (movement) using a peristaltic pump, stand, and containers for sampling and draining biomaterial. The results of the experiment showed that after the blood plasma flows through the hemosorbent, the concentration of albumin and globulin decreases. The obtained results indicate the high efficiency of the investigated hemosorbent in relation to all major immunoglobulin classes. The calculated sorption efficiency was $44.89(37.24 ; 46.27) \%$ for $\operatorname{IgG}, 31.83(31.73 ; 39.74) \%$ for $\operatorname{IgM}, 22.25(12.64 ; 25.08) \%$ for $\operatorname{IgA}$, and 13.91 $(9.76 ; 16.37) \%$ for IgE. The study revealed differences in the sorption efficiency for IgG subclasses. The amount of IgG-3 in plasma decreased after the experiments by more than $50 \%$ of the initial concentration, the
\end{abstract}


calculated sorption efficiency was $51.23(45.65 ; 63.84) \%$ for IgG-3, $31.25(26.54 ; 33.21) \%$ for IgG-2, 23.26 $(15.45 ; 25.30) \%$ for IgG-1, and $31.91(23.61 ; 33.25) \%$ for IgG-4. Thus, this hemosorbent can be recommended for the use in patients with diseases whose pathogenesis is associated with the participation of these immunoglobulins: autoimmune diseases, graft rejection, hypergammaglobulinemia, etc.

Keywords: hemosorbent, sorption, immunoglobulin G, blood plasma, sorption specificity.

\section{References}

1. Sueoka A., Ther. Apher., 1997, Vol. 1, iss. 3, pp. 271-283.

2. Wiesenhuter C., Irish B., Bertram J., J. Rheumatol., 1994, Vol. 21, iss. 5, pp. 804-812.

3. Braun N., Risler T., Ther. Apher., 1999, Vol. 3 , iss. 3, pp. 240-245.

4. Oka K., Nakaji S., Ide Y., Okumura S., Jpn. J. Artif. Organs., 1993, Vol. 22, pp. 194-197.

Рябцева Татьяна Владимировна - научный сотрудник, УО «Белорусский государственный медицинский университет», Минск

Макаревич Денис Александрович - к.б.н., научный сотрудник, ГНУ «Институт биоорганической химии НАН Беларуси», Минск

Старостин Александр Валерьянович научный сотрудник, ГУ «МНПЦ хирургии, трансплантации и гематологии», Минск
5. Pokrovsky S., Kuznetsova Y., Afanasieva O., Zvezdkin P., Therapeutic Apheresis and Dialysis, 2005, Vol. 9, iss. 5, pp. A38

6. Beena M.S., Chandy T., Sharma C.P., J Biomater.Appl., 1994, Vol. 8, iss. 4, pp. 385-403.

7. Napodano C., Marino M.-P., Stefanile A. et al., A Journal of Molecular and Cellular Immunology. Immunological investigations, 2020, No 11, pp. 1-19.

Ryabzeva Tatyana V. - Researcher, Belorussian state medical university, Minsk

Makarevich Denis A. - Ph.D. of Biological sciences, Research Associate, Institute of bioorganic chemistry NAN Belarus, Minsk, E-mail: demkarevich@yandex.ru

Starostin Alexander V. - Researcher, State Institution "Minsk Scientific and Practical Center for Surgery, Transplantology and Hematology", Minsk 